\title{
Sexual Risk Behavior Among Youths of Nepal: Further analysis of Nepal Demographic Health Survey 2016
}

\author{
Sumina Oli ${ }^{1}$, Dikshika Bhandari ${ }^{1}$, Sampurna Kakchapati ${ }^{1,2^{*}}$ \\ ${ }^{1}$ Department of Public Health, Nobel College, Pokhara University, Kathmandu, Nepal \\ ${ }^{2}$ Department of Research and Evaluation, Integral Research Center, Nepal
}

Received:

22 July 2020

Revised:

15 March 2021

Accepted:

24 March 2021

${ }^{*}$ Corresponding author kck_sampurna@yahoo. com

\begin{abstract}
Background: The period of youth is the time of major physical changes in the body that precedes psychosocial maturity. The curious mind of youths predisposes them to practice sexual risk behaviors. This study aims to identify the prevalence of sexual risk behavior and factors associated with sexual risk behaviors among youths of Nepal.
\end{abstract}

Methodology: This was a retrospective analysis of 6,524 youths aged 15-24 years using data obtained from the Nepal Demographic and Health Survey for the year 2016. The outcome were premarital sex, recent sexual activity and multiple sex partners and the determinants were socio-demographic characteristics and smoking status. Statistical analysis was done using chi-square tests to assess statistically significant associations between determinants and outcome. Multivariate logistic regression was performed to identify the most important determinant associated with the outcome.

Results: The prevalence of premarital sex among the youths was 5.2\%, 49.3\% were involved in recent sexual activity within four weeks and 5.5\% had multiple sex partners. Variables that were significantly associated with premarital sex included male gender $(\mathrm{AOR}=6.3,95 \% \mathrm{CI}=4.3,13.2)$ and smoking $(\mathrm{AOR}=2.4$, $95 \% \mathrm{CI}=1.8,3.16)$. Variables that were significantly associated with recent sexual activity included female gender $(\mathrm{AOR}=1.36,95 \% \mathrm{CI}=1.18,1.58)$, age $(\mathrm{AOR}=8.3,95 \% \mathrm{CI}=7.3,9.3)$, rural residence $(\mathrm{AOR}=1.4,95 \%$ $\mathrm{CI}=1.26,1.62)$, illiteracy $(\mathrm{AOR}=4.34,95 \% \mathrm{CI}=3.27,5.76)$, poor wealth index $(\mathrm{AOR}=0.6,95 \% \mathrm{CI}=0.5,0.68)$ and smoking $(\mathrm{AOR}=3.38,95 \% \mathrm{CI}=2.57,4.46)$. Variables that were significantly associated with multiple sex partners in the presence of other variables included male gender $(\mathrm{AOR}=5.5,95 \% \mathrm{CI}=2.58,7.05)$ and smoking $(\mathrm{AOR}=2.2,95 \% \mathrm{CI}=1.6,3.05)$.

Conclusion: The male and smoker youths were more likely to practice all forms of sexual risk behaviors. This study recommends the need for comprehensive sexuality education for youths with a focus on safer sex practices.

Keywords: Youths, premarital sex, sexual risk behaviors, Nepal

Tweetable Abstract: Sexual risk behaviours are drivers for the poor health outcomes among youths that can be upturned through inclusive sexuality education.

\section{Introduction}

Safe and healthy sexual behavior, including reproductive choice, not only play a key role in young people's health and wellbeing but are also salient public health issues [1]. The physical, sexual, psychological and social developmental changes occur during the transition from childhood to adulthood, these changes provide both opportunity and risk for healthy development; and one of those risks include sexual risk behaviors [2]. Sexual risk behaviors include premarital sex, early sexual initiation, unprotected sexual intercourse, sex with multiple partners, and unprotected sex with partners who are potential carriers of sexually transmitted infections (STIs) and Human immunodeficiency virus (HIV) [3].

Sex at an early age may harm the mental development of youth in several forms with a possible exchange of sexually transmitted diseases and getting pregnant at an early age [4]. Sexually active youths, aged 15-24 years are at a greater risk of experiencing ad- verse health and social outcomes including unplanned pregnancy, early maternity, abortion, or STIs than older sexually active populations $[5,6]$. With many youths initiating sexual intercourse and being engaged in risk behaviors during adolescence, it is a crucial time to measure youth's sexual behaviors as a way to inform and influence health services, and health education policy and practice at local, national and international levels [1].

Around 1.2 billion people, or one in six of the world's population, are adolescents aged 10 to 19 years and about 350 million adolescents are comprising about $22 \%$ of the population in the countries of the South-East Asia Region (SEAR) [2]. Youths (15-24 years) account for $50 \%$ of new cases of HIV among which five to six thousand youths become infected every day, most of them in low-income countries [7].

The prevalent gender disparities, early marriage, decreasing age 
of sexual initiation, poverty, and increasing rates of multiple and concurrent partnerships have led to higher sexual risk behaviors among youths resulting in the HIV epidemic and the highest rate of adolescent pregnancy in SEAR [8].

The youth who initiate sexual activity early may lack knowledge about or have difficulty obtaining, using, or negotiating contraception and may put themselves at risk for unplanned pregnancy or STIs [9]. The literature also suggest that early initiators take more sexual risks, including having multiple sexual partners and having casual partners, both of which are risks for sexually transmitted infections [10].

The first Global School-based Student Health Survey (GSHS) in Nepal reported that $20.8 \%$ adolescent students (male $(22.6 \%)$, female $(18.3 \%)$ ) had sexual intercourse in their life; $66.9 \%$ adolescent's students (male $(58.5 \%)$, female $(80.0 \%)$ ) had first sexual intercourse before age 14 years and $1.9 \%$ of adolescents' students (male $(2.7 \%)$, female $(0.9 \%)$ ) had multiple sex partners in the past 12 months [11]. Likewise, the National Adolescent and Youth Survey (NAYS) carried out in 2010/11 where 14,754 Adolescents \& Youths aged 10-24 years were enrolled found that $13 \%$ of the adolescents and youths had premarital sex [12]. Similarly, out of total HIV-positive cases reported in 2008 in Nepal, three in four were found to have unsafe sexual practices and about $20 \%$ of the total HIV cases were in the age group of 15-24 years [13]. The evaluation database of United Nations Children's Fund (UNICEF) shows that almost 20 percent of teenagers of Nepal considered premarital sex as proper, one in five boys and nearly one in ten girls had a sexual experience, unprotected sex had led to $14 \%$ pregnancy rate and $22 \%$ sexually transmitted infection rate in boys and $13 \%$ rate in girls [14].

The ever-increasing trend of adolescent pregnancy, STI, and HIV/AIDS among youths may be related to sexual risk behaviors such as premarital sex, multiple sex partners, and recent sexual activities. The need to identify such behavior is imperative in developing countries like Nepal yet less is known about the prevalence of sexual risk behavior and its associated factors among youths. Therefore, this study aims to determine the prevalence of sexual risk behaviors such as premarital sex, recent sexual activity, and multiple sex partner among the youth population of Nepal and its determinants. This analysis can furthermore aid scholars to evaluate the factors that impact sexual risk behaviors among youths in Nepal.

\section{Materials and methods}

The study used the data from survey data files of Nepal Demographic Health Survey 2016, which was implemented by New ERA under the leadership of the Ministry of Health and Population. Out of 16,925 respondents, 6,524 were youths between the 15-24 age group and were included in further analysis. The outcome variables were premarital sex, recent sexual activity, and multiple sex partners. Premarital sex, defined as voluntary sexual intercourse between unmarried persons [15], recent sexual activity, defined as a sexual activity within four weeks preceding the survey, and multiple sex partners defined as having two or more than two sexual partners [16]. Study variables were gender, age, province, residence, religion, literacy, educational status, wealth index, marital status and smoking status. Data between the age group of 15-24 years of both male and female were compiled first and analyzed using percent and frequency tables and statistical tests were carried out using chi-square and logistic regression. Pearson's chi-squared test was used to assess the statistical significance of the association between the outcomes and study variables. Variables that were significant in the bivariate analysis were included in the multivariate logistic regression. The $\mathrm{p}$-value of less than 0.05 was used to define statistical significance. Adjusted odds ratios (AOR), as well as their 95\% Confidence Intervals (95\% CI), were used to depict the relationship between study variables and outcome variables. The statistical analysis and graph were created using the R program.

\section{Results}

The prevalence of premarital sex among the youths was $5.2 \%$, nearly half of the youths (49.3\%) were involved in recent sexual activity in the last four weeks and 5.5\% of youths had multiple sex partners. Figure 1 shows, the relationship between different forms of sexual risk behaviors in the form of a proportional Venn diagram. Overall, about 4.5 percent of youths had recent sexual activity and multiple sex partners, $4.2 \%$ youths had recent sexual activity and premarital sex and $3.6 \%$ of youths had both premarital sex and multiple sex partners. About 2.6 percent of youths had all three forms of sexual risk behaviors i.e., recent sexual activity, premarital sex and multiple sex partners. The most common sexual risk behavior was recent sexual activity (49.3\%) followed by multiple sexual partners (5.5\%) and premarital sex $(5.2 \%)$.

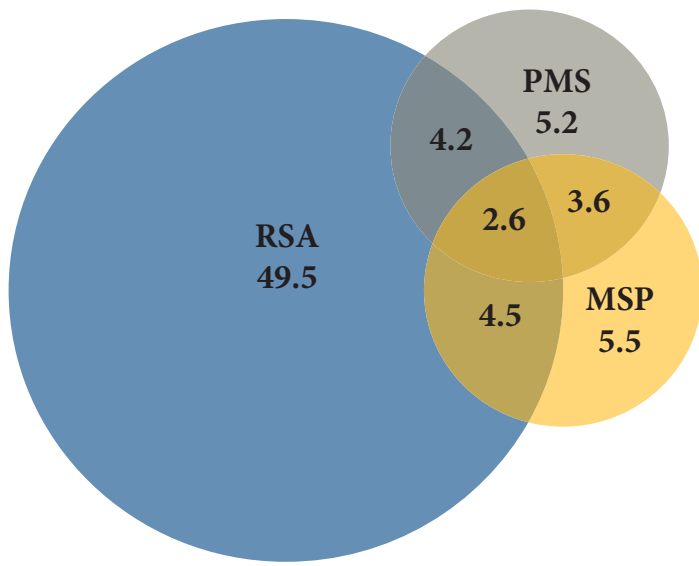

RSA: Recent Sexual Activity; MSP: Multiple Sex Partners; PMS: Premarital Sex

Figure 1. Proportional Venn diagram illustrating the overlapping between the different forms of sexual risk behaviors

Table 1 shows the association between study variables and premarital sex among youths. Gender, province, educational status, wealth index, marital status and smoking status were found significantly associated with premarital sex in bivariate analysis. Premarital sex was found higher among male youths compared to female youths. While comparing the proportion of premarital sex among youths in seven provinces of Nepal, the highest proportion of premarital sex was found among youths of province number 5 followed by Gandaki province with least in Karnali province. Likewise, literate youths, youths belonging to the rich wealth index, unmarried youths, and youths who smoke had a higher proportion of premarital sex. 
Table 1: Association between study variables and premarital sex

\begin{tabular}{|c|c|c|c|}
\hline \multirow[t]{2}{*}{ Characteristics } & \multicolumn{2}{|c|}{ Premarital sex } & \multirow[t]{2}{*}{ p-value } \\
\hline & No n (\%) & Yes n (\%) & \\
\hline Gender & & & $<0.05$ \\
\hline Male & $1,273(79.7)$ & $324(20.3)$ & \\
\hline Female & 4,914 (99.7) & $13(0.3)$ & \\
\hline Age group & & & 0.560 \\
\hline $15-19$ years & 3,405 (95) & $180(5)$ & \\
\hline 20-24 years & $2,782(94.7)$ & $157(5.3)$ & \\
\hline Province & & & 0.043 \\
\hline Province No. 1 & $872(95.2)$ & $44(4.8)$ & \\
\hline Province No. 2 & $1,025(95.6)$ & $47(4.4)$ & \\
\hline Bagmati & $780(95)$ & $41(5)$ & \\
\hline Gandaki & $746(93.4)$ & $53(6.6)$ & \\
\hline Lumbini & $985(93.3)$ & $71(6.7)$ & \\
\hline Karnali & $894(95.8)$ & $39(4.2)$ & \\
\hline Sudurpashim & $885(95.5)$ & $42(4.5)$ & \\
\hline Residence & & & 0.686 \\
\hline Urban & $4,014(94.9)$ & $215(5.1)$ & \\
\hline Rural & $2,173(94.7)$ & $122(5.3)$ & \\
\hline Religion & & & 0.381 \\
\hline Hindu & $5,337(94.9)$ & $285(5.1)$ & \\
\hline Others & $850(94.2)$ & $52(5.8)$ & \\
\hline Education status & & & 0.001 \\
\hline Illiterate & 445 (98) & $9(2)$ & \\
\hline Literate & $5,742(94.6)$ & $328(5.4)$ & \\
\hline Wealth Index & & & 0.007 \\
\hline Poor & $2,633(95.7)$ & $117(4.3)$ & \\
\hline Middle & $1,281(94.8)$ & $70(5.2)$ & \\
\hline Rich & $2,273(93.8)$ & $150(6.2)$ & \\
\hline Marital status & & & $<0.05$ \\
\hline Unmarried & $3,303(90.7)$ & $337(9.3)$ & \\
\hline Married & $2,850(100)$ & $0(0)$ & \\
\hline Others & $34(100)$ & $0(0)$ & \\
\hline Smoking status & & & $<0.05$ \\
\hline No & $5,918(96.4)$ & $224(3.6)$ & \\
\hline Yes & $269(70.4)$ & $113(29.6)$ & \\
\hline Total & $6,187(94.8)$ & $337(5.2)$ & \\
\hline
\end{tabular}

Table 2 depicts the association between study variables and recent sexual activity among youths. Among all, 49.3 percent of the youths were involved in recent sexual activity. Gender, age group, province, residence, educational status, wealth index, marital status, and smoking status were significantly associated with recent sexual activity of youths in bivariate analysis. Among all, 50.9\% of female and $44.3 \%$ of male youths were involved in recent sexual activity. Likewise, the youths of the age group 20-24 years were more involved in recent sexual activity than the 15-19 age group. A higher percentage of youths in rural residence were involved in recent sexual activity than youths of urban. Among all provinces, the youths of Karnali province were more engaged in recent sexual activity. Similarly, the illiterate youths, youths of the middle wealth index, married youths and smokers were more involved in recent sexual activity.

Table 2: Association between study variables and recent sexual activity

\begin{tabular}{|c|c|c|c|}
\hline \multirow[t]{2}{*}{ Characteristics } & \multicolumn{2}{|c|}{ Sexual Activity } & \multirow[t]{2}{*}{ p-value } \\
\hline & Not active n (\%) & Active n (\%) & \\
\hline Gender & & & $<0.05$ \\
\hline Male & $890(55.7)$ & $707(44.3)$ & \\
\hline Female & $2,418(49.1)$ & $2,509(50.9)$ & \\
\hline Age group & & & $<0.05$ \\
\hline 15-19 years & $2,586(72.1)$ & 999 (27.9) & \\
\hline 20-24 years & $7,22(24.6)$ & $2,217(75.4)$ & \\
\hline Province & & & $<0.05$ \\
\hline Province No. 1 & $503(54.9)$ & $413(45.1)$ & \\
\hline Province No. 2 & $457(42.6)$ & $615(57.4)$ & \\
\hline Bagmati & $498(60.7)$ & $323(39.3)$ & \\
\hline Gandaki & $422(52.8)$ & $377(47.2)$ & \\
\hline Lumbini & $525(49.7)$ & $531(50.3)$ & \\
\hline Karnali & $381(40.8)$ & $552(59.2)$ & \\
\hline Sudurpashim & $522(56.3)$ & $405(43.7)$ & \\
\hline Residence & & & $<0.05$ \\
\hline Urban & $2,279(53.9)$ & $1,950(46.1)$ & \\
\hline Rural & $1,029(44.8)$ & $1,266(55.2)$ & \\
\hline Religion & & & 0.364 \\
\hline Hindu & $2,838(50.5)$ & $2,784(49.5)$ & \\
\hline Others & $470(52.1)$ & $432(47.9)$ & \\
\hline Education status & & & $<0.05$ \\
\hline Illiterate & $73(16.1)$ & $381(83.9)$ & \\
\hline Literate & $3,235(53.3)$ & $2,835(46.7)$ & \\
\hline Wealth Index & & & $<0.05$ \\
\hline Poor & $1,316(47.9)$ & $1,434(52.1)$ & \\
\hline Middle & $620(45.9)$ & $731(54.1)$ & \\
\hline Rich & $1,372(56.6)$ & $1,051(43.4)$ & \\
\hline Marital status & & & $<0.05$ \\
\hline Unmarried & $3,303(90.7)$ & $337(9.3)$ & \\
\hline Married & $3(0.1)$ & 2,847 (99.9) & \\
\hline Others & $2(5.9)$ & $32(94.1)$ & \\
\hline Smoking status & & & $<0.05$ \\
\hline No & $3,195(52)$ & $2,947(48)$ & \\
\hline Yes & $113(29.6)$ & $269(70.4)$ & \\
\hline Total & $3,308(50.7)$ & $3,216(49.3)$ & \\
\hline
\end{tabular}


Among total youths, 3324(50.9\%) youths had no sexual partners and were excluded in the analysis, so only $3200(49 \%)$ youths were included in this analysis. Out of 3200 youths, 358(11.2\%) youths had multiple sex partners. Table 3 shows the association between study variables and multiple sex partners.

Table 3: Association between study variables and multiple sex partner

\begin{tabular}{|c|c|c|c|}
\hline \multirow[t]{2}{*}{ Characteristics } & \multicolumn{2}{|c|}{ Multiple Sex Partner } & \multirow[t]{2}{*}{ p-value } \\
\hline & No n (\%) & Yes n (\%) & \\
\hline Gender & & & $<0.05$ \\
\hline Male & $365(52.7)$ & $328(47.3)$ & \\
\hline Female & $2,477(98.8)$ & $30(1.2)$ & \\
\hline Age group & & & 0.884 \\
\hline 15-19 years & $884(88.9)$ & $110(11.1)$ & \\
\hline 20-24 years & $1,958(88.8)$ & $248(11.2)$ & \\
\hline Province & & & 0.014 \\
\hline Province No. 1 & $367(89.1)$ & $45(10.9)$ & \\
\hline Province No. 2 & $570(93)$ & $43(7)$ & \\
\hline Bagmati & $287(89.4)$ & $34(10.6)$ & \\
\hline Gandaki & $322(86.3)$ & $51(13.7)$ & \\
\hline Province No. 5 & $460(87)$ & $69(13)$ & \\
\hline Karnali & $481(87.6)$ & $68(12.4)$ & \\
\hline Sudurpashim & $355(88.1)$ & $48(11.9)$ & \\
\hline Residence & & & 0.242 \\
\hline Urban & $1,711(88.3)$ & $227(11.7)$ & \\
\hline Rural & $1,131(89.6)$ & $131(10.4)$ & \\
\hline Religion & & & 0.410 \\
\hline Hindu & $2,466(89)$ & $305(11)$ & \\
\hline Others & $376(87.6)$ & $53(12.4)$ & \\
\hline Education status & & & $<0.05$ \\
\hline Illiterate & $362(95.3)$ & $18(4.7)$ & \\
\hline Literate & $2,480(87.9)$ & $340(12.1)$ & \\
\hline Wealth Index & & & 0.053 \\
\hline Poor & $1,284(90.1)$ & $141(9.9)$ & \\
\hline Middle & $648(88.9)$ & $81(11.1)$ & \\
\hline Rich & $910(87)$ & $136(13)$ & \\
\hline Marital status & & & $<0.05$ \\
\hline Unmarried & $160(48.2)$ & $172(51.8)$ & \\
\hline Married & $2,654(93.6)$ & $182(6.4)$ & \\
\hline Others & $28(87.5)$ & $4(12.5)$ & \\
\hline Smoking status & & & $<0.05$ \\
\hline No & $2,721(92.6)$ & $217(7.4)$ & \\
\hline Yes & $121(46.2)$ & $141(53.8)$ & \\
\hline Total & $2,842(88.8)$ & $358(11.2)$ & \\
\hline
\end{tabular}

Gender, province, education status, marital status, and smoking status were found significantly associated with multiple sexual partners in bivariate analysis. Multiple sexual partners were a higher among males compared to females. Among all provinces, youths of Gandaki province had a higher percent of multiple sex partners. Similarly, youths who were literate had a higher proportion of multiple sex partners. Unmarried youths had a higher percent of multiple sex partners compared to married youths. Likewise, the youths who smoked had a higher percent of multiple sex partners as compared to non-smokers.

Gender, education status, wealth index, and smoking status significant with premarital sex in bivariate analysis were included in multivariate logistic regression. Table 4 shows an association between study variables and premarital sex among youths. In multivariate analysis, gender and smoking status of youths were associated with premarital sex $(\mathrm{P}$ value $<0.001)$. The male youths were six times more likely to have premarital sex $(A O R=6.3,95 \% \mathrm{CI}=4.3$, 13.2) than female youths. Likewise, the youths who were smokers were two times more likely to have premarital sex $(\mathrm{AOR}=2.4,95 \%$ $\mathrm{CI}=1.8,3.16)$ than nonsmokers.

Table 4: Multivariate logistic regression models examining correlates of premarital sex among youths in Nepal

\begin{tabular}{lcc}
\hline Study variables & Premarital sex & p-value \\
\hline Gender & & 0.03 \\
Female & Ref & \\
Male & $6.3(4.3-13.2)$ &
\end{tabular}

Educational status

0.67

Illiterate

Ref

Literate

$1.08(0.51-2.27)$

Wealth index

Poor

Ref

Middle

$1.19(0.85-1.67)$

Rich

$1.26(0.95-1.65)$

Smoking status

No

Ref

Yes

$2.4(1.8-3.16)$

Similarly, gender, age group, residence, province, educational status, wealth index, marital status, and smoking status significantly associated with recent sexual activity of youths in bivariate analysis were included in the multivariate logistic regression. Table 5 shows an association between study variables and recent sexual activity among youths.

Female youths were found to be engaged more in recent sexual activity $(\mathrm{AOR}=1.36,95 \% \mathrm{CI}=1.18,1.58)$ than male youths. The youths who were smokers were three times more likely to have been involved in recent sexual activity $(\mathrm{AOR}=3.38,95 \% \mathrm{CI}=2.57$, 4.46) than nonsmokers. Likewise, the youths of the age group 20 24 years were eight times more likely to be involved in recent sexual activity $(\mathrm{AOR}=8.3,95 \% \mathrm{CI}=7.3,9.3)$ than youths of the $15-19$ age groups. The youths of rural were found to be engaged in recent sexual activity $(\mathrm{AOR}=1.4,95 \% \mathrm{CI}=1.26,1.62)$ than youths residing in an urban area. The illiterate youths were found four times more 
likely to be involved in recent sexual activity (AOR $=4.34,95 \%$ $\mathrm{CI}=3.27,5.76)$ than literate youths. Compared with youths with the rich wealth index, youths of the poor wealth index were more involved in recent sexual activity ( $\mathrm{AOR}=0.6,95 \% \mathrm{CI}=0.5,0.68$ ).

Table 5: Multivariate logistic regression models examining correlates of recent sexual activity among youths in Nepal

\begin{tabular}{lcc}
\hline Study variables & Recent sexual activity & p-value \\
\hline Gender & & 0.04 \\
Female & $1.36(1.18-1.58)$ & \\
Male & Ref & \\
Age group & & 0.001 \\
$15-19$ & Ref & \\
$20-24$ & $8.3(7.3-9.3)$ & \\
Residence & & 0.03 \\
Urban & Ref & \\
Rural & $1.4(1.26-1.62)$ & \\
Educational status & & 0.002 \\
Illiterate & $4.34(3.27-5.76)$ & \\
Literate & Ref & \\
Wealth index & & \\
Rich & Ref & 0.65 \\
Middle & $1.01(0.87-1.18)$ & 0.04 \\
Poor & $0.6(0.5-0.68)$ & 0.002 \\
Smoking status & & \\
No & Ref & \\
Yes & $3.38(2.57-4.46)$ & \\
\hline
\end{tabular}

Gender, education status, marital status, and smoking status significantly associated with multiple sex partners in bivariate analysis were included in the multivariate logistic regression. Table 6 shows an association between study variables and multiple sex partners among youths. The male youths were five times more likely to have multiple sex partners (AOR=5.5, 95\% $\mathrm{CI}=2.58,7.05)$ than female youths. The youths who were smokers were two times more likely to have multiple sex partners $(\mathrm{AOR}=2.2,95 \% \mathrm{CI}=1.6,3.05)$ than non-smokers.

\section{Discussion}

The study assessed the prevalence of sexual risk behaviors (premarital sex, recent sexual activity, and multiple sex partners) and factors associated with sexual risk behaviors among youths using data from the Nepal Demographic Health Survey (NDHS) 2016. This study has shed light on the sexual risk behavior pattern existing among youths of Nepal.

The study findings revealed that the proportion of premarital sex and multiple sex partners among the youths were $5.2 \%$ and $5.5 \%$ respectively. A similar study revealed that late adolescence affair was associated with premarital sex behavior and factors for having premarital sex included age, sex, peer relationship/love, and affair [17]. Likewise, the survey data from many developed and de-
Table 6: Multivariate logistic regression models examining correlates of multiple sex partners among youths in Nepal

\begin{tabular}{lcc}
\hline Study variables & Multiple sex partners & p-value \\
\hline Gender & & 0.03 \\
Female & Ref &
\end{tabular}

Male $\quad 5.5(2.58-7.05)$

Educational status

Illiterate

Ref

Literate

1.05 (0.57-1.94)

Marital status

Others

Ref

Unmarried

$1.34(0.34-5.34)$

0.34

Married

$0.8(0.2-3.2)$

0.27

Smoking status

No

0.003

Yes

Ref

$2.2(1.6-3.05)$

veloping countries at the beginning of the 21 st century showed that more than two-thirds of the youths had premarital sex while still in their teens; even in the countries like India, Indonesia and Iran, where premarital sex is still a taboo, its prevalence is in the increase due to the movement away from marriage to cohabitation [18].

In multivariate analysis, male gender and smoking were associated with all outcome variables. Male gender was found to increase the likelihood of premarital sex and the multiple sex partners among youths as consistent with numerous studies $[19,20]$. In many countries, particularly in the developing world societal sexual expectation for boys and girls varies where men are expected to be heterosexually active while women are expected to keep their virginity until marriage and sex outside marriage is forbidden for girls and women [21]. In the Nepali cultural context, sex before marriage is forbidden [4].

Smoking was associated with all three sexual risk behaviors (premarital sex, recent sexual activity, and multiple partners). These findings were aligned with previous studies that found that cigarette smoking and sexual risk behaviors are correlated with each other [22, 23]. Previous research has revealed that youths with high rates of aggressive-disruptive behaviors and attention problems at school entry are more likely to engage in problem behaviors in middle school; these behaviors are associated with early initiation of sexual activity [24]. The study from National Youth Risk Behavior Survey (YRBS) 1999-2007 in Nepal showed a positive association between cigarette use and the number of sexual partners; as the frequency of cigarette use increased so did the magnitude of odds of the higher number of sexual partners [25].

Among all 49.3 percent of the youths were engaged in recent sexual activity in the last four weeks. Higher age groups (20-24), female youths, youths from rural areas, illiterate youths, and youths of poor wealth quintile had higher odds of having recent sexual activity in multivariate analysis. A striking result was that female youths were found to be more involved in recent sexual activity than the male which can be related to the early marriage practices of the female in Nepal. The average age of female marriage in Nepal 
is 17.9 years and that of the males is 21.7 years [16]. Moreover, in our study, half of the female youths were married. Similarly, the youths of age group 20-24 years were eight times more likely to be engaged in recent sexual activity than those of 15-19 years. It was observed from similar studies that the youths aged 20-24 years were more likely to experience premarital sex than those between 15-19 years, which makes this group more sexually active [17]. A study conducted in the rural area of Nepal found that more than one-fourth of youths were sexually active and engaged in multiple sexual relations [13]. In this study also youths of the rural area were found to be more involved in recent sexual activity than youths of urban. Similarly, illiterate youths were more engaged in recent sexual activity than literate youths. The finding corroborates with a similar study where youths who had little education were more likely to initiate sexual intercourse early and involve in sexual risk behaviors than educated [26]. Similarly, youths with the poor wealth index were found to be engaged more in recent sexual activity. A similar pattern was observed in a study where poverty was associated with sexual risk behavior [27].

The cross-sectional nature of the data limits causal inference while the self-reported nature could result in under-reporting of the sexual risk behavior, especially given that the Nepalese society generally detests sexual intercourse among unmarried youth. We also examined the relationship between smoking habits and sexual activity cross-sectionally, causal inferences cannot be made. Future studies should investigate the effects of smoking habits on sexual activity among youths.

\section{Conclusion}

The study concluded that nearly half $(49.3 \%)$ of the youths were indulged in recent sexual activity within four weeks. Premarital sexual intercourse and multiple sex partners were common among male youths and who were smokers. This evidence suggested that youths are exposed to health hazards due to their sexual risk behaviors; hence comprehensive sexuality education should be provided. The study highlights the need for concentrated efforts to aware the youths focusing on sexual health and reproductive health with a major emphasis on delayed sexual debut, reduction in the number of partners, and use of condoms for every sexual act.

\section{Disclosure}

The authors declare no conflicts of interest in this work.

\section{References}

1. Young, H., Költő, A., Reis, M. et al. Sexual Health questions included in the Health Behaviour in School-aged Children (HBSC) Study; an international methodological pilot investigation. BMC Med Res Methodol. 2016, 16(1):169. Published 2016 Dec 5. doi: 10.1186/s12874-016-0270-8

2. WHO. South-East Asia. Adolescent Health. 2019. [cited 2019 Jul 9]. Available from:https://www.who.int/southeastasia/health-topics/adolescent-health

3. Bengel, J. Sexual Risk Behaviours. International Encyclopedia of the Social and Behavioural Sciences.2002. 14012-14018.

4. Shakya, VD. Trends in Sexual Practices of Nepalese Youth over Time 20062016. TUJ. 2018, 32(1). 185-196. https://doi.org/10.3126/tuj.v32i1.24785

5. Centers for Disease Control and Prevention (CDCP). Sexually transmitted disease surveillance 2010. [Cited 2019 Sep 10]. Available from: http://www. cdc.gov/std/stats10/surv2010.pdf.
6. Department of Health and social care. Abortion statistics for England and Wales. 2013. [cited 2019 Jul 12]. Available from: https://www.gov.uk/government/collections/abortion-statistics-for-england-and-wales.

7. WHO. Preventing HIV/AIDS in young people. 2019. [cited 2019 Aug 13]. Available from: https://www.who.int/maternal_child_adolescent/documents/ trs_938/en/

8. Advancing partners and communities. Dashboard on Youth Sexual \& Reproductive Health: South \& Southeast Asia. 2011. [cited 2020 Oct 2] Available from: https://www.advancingpartners.org/resources/dashboards-youth/dashboard-youth-sexual-reproductive-health-south-southeast-asia)

9. Finer, LB., Philbin, JM. Sexual initiation, contraceptive use, and pregnancy among young adolescents. Pediatrics.2013, 131:886-891. [PMC free article] [PubMed] [Google Scholar]

10. Adimora, AA., Schoenbach, VJ., Taylor, EM., Khan, MR., Schwartz, RJ. Concurrent partnerships, nonmonogamous partners, and substance use among women in the United States. Am. J. Public Health. 2011, 101:128-136. [PMC free article] [PubMed] [Google Scholar]

11. Aryal, KK., Bista, B., Khadka, BB., et al. Global School Based Student Health Survey Nepal 2015. Kathmandu, Nepal: Nepal Health Research Council, 2017.

12. Ministry of Health and Population (MoHP), Nepal Adolescents and Youth Survey 2010/11, Kathmandu, Nepal: Ministry of Health and Population, 2012.

13. Paudel, M., Mehata, S., Subedi, N. et al. Sexual Behaviour among School Youths in a Rural Far-western District of Nepal. Health Prospect: J. Public Health. 2014, 12 (2).37-41. https://doi.org/10.3126/hprospect.v12i2.9873

14. UNICEF. Evaluation database. A survey of teenagers in Nepal. 2001. [cited 2018 feb 12] Available from: https://www.unicef.org/evaldatabase/index_21339.html

15. Shahid $\mathrm{KH}, \mathrm{AH} \mathrm{SH}$, Wahab HA. Adolescents and premarital sex: perspectives from family ecological context. Int J Stud Child Women Elderly Disabled .2017; 1.157-165.

16. Ministry of Health, New ERA and ICF: Nepal demographic and health survey. Kathmandu, Nepal: Ministry of health, 2016.

17. BC, GB, Basel, PL. Premarital Sex Behaviors among College Youths of Kathmandu, Nepal. Kathmandu Univ Med J. 2013; 41(1):27-31.

18. Chamie, J. Premarital Sex: Increasing Worldwide. Inter press service News Agency. 2018. [cited 2019 Jun 8]. Available from:http://www.ipsnews. net/2018/04/premarital-sex-increasing-worldwide/

19. Khanal, P. Sexual Behaviour among Higher Secondary School Students of Kathmandu Metropolitan City. Health Prospect: J. Public Health. 2018, 11, 15-18. https://doi.org/10.3126/hprospect.v11i0.7424

20. Adhikari, N., Adhikari, S. Attitude towards Premarital Sex among Higher Secondary Students in Pokhara Sub-Metropolitan City. J Community Med Health Educ. 2017.Vol 7(5). DOI: 10.4172/2161-0711.1000564

21. Doku, D. Substance use and risky sexual behaviors among sexually experienced Ghanaian youth. BMC Public Health. 12, 571 (2012). https://doi. org/10.1186/1471-2458-12-571

22. Lam, T., Stewart, $S$ and Ho, L. Prevalence and correlates of smoking and sexual activity among Hong Kong adolescents. J Adolesc Health.2001, 29(5):352-358

23. Pahl. K., Brook, D., Morojele, N. et al. Nicotine dependence and problem behaviors among urban South African adolescents. J. Behav. Med.2010, 33(2):101-109

24. Schofield H-LT, Bierman KL, Heinrichs B, et al. Predicting Early Sexual Activity with Behavior Problems Exhibited at School Entry and in Early Adolescence. J. Abnorm. Child Psychol. 2008, 36(8):1175-1188.

25. Cavazos-Rehg, P. A., Krauss, M. J., Spitznagel, E. L. et al. Number of sexual partners and associations with initiation and intensity of substance use. AIDS Behav .2011, 15(4), 869-874. https://doi.org/10.1007/s10461-010-9669-0 
26. Singh, S., Darroach, JE., Frost, JJ. et al. Socioeconomic Disadvantage and Adolescent Women's Sexual and Reproductive Behavior; The Case of Five Developed Countries. Fam Plann Perspect. 2001, 33(6):251-258 \& 289.

27. Silas, J. Poverty and Risky Sexual Behaviors: Evidence from Tanzania. Demographic and Health Survey.2013. [Cited 2020 Apr 28]. Available from: https:// dhsprogram.com/pubs/pdf/WP88/WP88.pdf. 